\title{
Genetic and cytometric analyses of subcutaneous adipose tissue in patients with hemophilia and HIV-associated lipodystrophy
}

Takanobu Mashiko ${ }^{1,2}$, Kunihisa Tsukada ${ }^{3}$, Hitomi Takada ${ }^{4}$, Szu-Hsien Wu ${ }^{2}$, Koji Kanayama ${ }^{2}$, Rintaro Asahi ${ }^{1}$, Masanori Mori ${ }^{1}$, Akira Kurisaki ${ }^{4}$, Shinichi $\mathrm{Oka}^{3}$ and Kotaro Yoshimura ${ }^{1 *}$ (i)

\begin{abstract}
Background: The authors recently performed plastic surgeries for a small number of patients with hemophilia, HIV infection, and morphologic evidence of lipodystrophy. Because the pathophysiological mechanism of HIV-associated lipodystrophy remains to be elucidated, we analyzed subcutaneous adipose tissues from the patients.

Methods: All six patients had previously been treated with older nucleoside analogue reverse-transcriptase inhibitors (NRTIs; stavudine, didanosine or zidovudine). Abdominal and inguinal subcutaneous fat samples were obtained from the HIV + patients with hemophilia and HIV - healthy volunteers ( $n=6$ per group), and analyzed via DNA microarray, real-time PCR, flow cytometry and immunohistochemistry.

Results: The time from initial NRTI treatment to collecting samples were 21.7 years in average. Cytometric analysis revealed infiltration of inflammatory M1 macrophages into HIV-infected adipose tissue and depletion of adiposederived stem cells, possibly due to exhaustion following sustained adipocyte death. Genetic analysis revealed that adipose tissue from HIV+ group had increased immune activation, mitochondrial toxicity, chronic inflammation, progressive fibrosis and adipocyte dysfunction (e.g. insulin resistance, inhibited adipocyte differentiation and accelerated apoptosis). Of note, both triglyceride synthesis and lipolysis were inhibited in adipose tissue from patients with HIV.

Conclusions: Our findings provide important insights into the pathogenesis of HIV-associated lipodystrophy, suggesting that fat redistribution may critically depend on adipocytes' sensitivity to drug-induced mitochondrial toxicity, which may lead either to atrophy or metabolic complications.
\end{abstract}

Keywords: Human immunodeficiency virus, HIV-associated lipodystrophy, Lipoatrophy, Gene analysis, Adiposederived stem cell, Macrophage

*Correspondence: kotaro-yoshimura@umin.ac.jp

1 Department of Plastic Surgery, Jichi Medical University, 3311-1, Yakushiji, Shimotsuke-Shi, Tochigi 329-0498, Japan

Full list of author information is available at the end of the article

\section{Introduction}

More than 30 years have passed since 1431 hemophilia patients in Japan were infected with human immunodeficiency virus type 1 (HIV-1) after receiving transfusions of contaminated, unheated blood products [1]. The survival rate for patients living with HIV has dramatically improved alongside recent advancements in antiretroviral therapy (ART) [2], however, some hemophilia patients original author(s) and the source, provide a link to the Creative Commons licence, and indicate if changes were made. The images or other third party material in this article are included in the article's Creative Commons licence, unless indicated otherwise in a credit line to the material. If material is not included in the article's Creative Commons licence and your intended use is not permitted by statutory regulation or exceeds the permitted use, you will need to obtain permission directly from the copyright holder. To view a copy of this licence, visit http://creativecommons.org/licenses/by/4.0/. The Creative Commons Public Domain Dedication waiver (http://creativeco mmons.org/publicdomain/zero/1.0/) applies to the data made available in this article, unless otherwise stated in a credit line to the data. 
infected with HIV still suffer from lipodystrophy which is HIV-associated adverse effects of ART. And unfortunately, the precise mechanisms behind the development of lipodystrophy remains unrevealed.

After the introduction of ART in the mid-1990s, HIV-associated lipodystrophy was quickly identified as a significant adverse effect. It includes morphological changes (peripheral lipoatrophy and central obesity) and metabolic changes (dyslipidemia, insulin resistance, and hyperglycemia), affecting up to $80 \%$ of patients [3, 4]. Facial lipoatrophy and other body changes can lead to low self-esteem and poor medication adherence [5], while the metabolic complications of lipodystrophy have been associated with an increased risk of cardiovascular disease [6]. Previous studies have shown that antiretroviral drugs, especially older nucleoside analogue reversetranscriptase inhibitors (NRTIs), provoke lipodystrophy [7]. It has been demonstrated that NRTI-induced mitochondrial toxicity is a primary cause of lipoatrophy [8], and long-term use of older NRTIs is closely linked to the development of severe lipoatrophy [9].

Although older NRTIs are rarely used in the current ART regimens, we need to continue treatment of the hemophilia patients who now suffer from HIV-associated lipodystrophy, for instance, management of facial lipoatrophy by filler injection $[10,11]$ or autologous fat grafting $[12,13]$. However, publicly available data including gene expression from HIV-infected hemophilia patients is still limited. Therefore, this study was designed to investigate genetic trends and differential protein expression in adipose tissues from Japanese hemophilia patients with HIV-1 and facial lipoatrophy who were treated with old NRTIs, to reveal new insights into the pathogenesis of HIV-associated lipodystrophy.

\section{Methods}

\section{Participants}

This study was approved by the ethics committee from the institutional review board of National Center for Global Health and Medicine (NCGM; Tokyo, Japan) (NCGM-G-001598-00). Patients were recruited from the AIDS Clinical Center of NCGM if they granted informed consent and met the following inclusion criteria; (1) were infected with HIV-1 after receiving unheated blood products to treat hemophilia, (2) received an ART regimen including stavudine, didanosine or zidovudine (old NRTIs), (3) had plasma viral loads below 200 HIV-RNA copies/mL, and (4) had lipodystrophy presenting clinically evident facial lipoatrophy. Six patients met these criteria and were included in this prospective, open-label study (2014-2018; clinical trial number: UMIN000020379). Additionally, six HIV-negative, healthy male volunteers were enrolled in this study to obtain reference control data after providing their informed consent.

\section{Clinical specimens of adipose tissue}

The six patients with HIV-associated facial lipodystrophy underwent liposuction of subcutaneous abdominal fat to enable lipotransfer for facial contouring. The lipoaspirates were purified by centrifugation at $1200 \times g$ for $3 \mathrm{~min}$, the supernatant was discarded and the remaining fat portion was used for cellular analyses. In addition, a $1-\mathrm{cm}^{3}$ sample of subcutaneous inguinal fat was collected from each of the six patients for genetic and histologic analyses. Also, HIV-negative lipoaspirates and excised fatty tissue were collected from the abdominal fat and inguinal fat of the six healthy volunteers, respectively, after obtaining informed consent before the procedure.

\section{Stromal vascular fraction isolation and flow cytometry}

The stromal vascular fraction (SVF) was isolated from aspirated abdominal fat as previously described [14]. Briefly, each tissue was washed and digested in phosphate-buffered saline containing $0.075 \%$ collagenase (Wako Pure Chemicals, Osaka, Japan) for $30 \mathrm{~min}$ at $37^{\circ} \mathrm{C}$ in a shaking water bath. After centrifugation $(800 \times g$ for $10 \mathrm{~min}$ ) and resuspension of the cell pellets, the SVF was obtained by filtering the cell suspension through a series of 100-, 70-, and 40- $\mu \mathrm{m}$ meshes (Millipore, Burlington, MA). Cell counts and viability were measured with an automated cell counter (NucleoCounter NC-100, ChemoMetec, Allerod, Denmark). The SVF samples were examined by flow cytometry using monoclonal antibodies against: CD45-fluorescein isothiocyanate (FITC), CD31-phycoerythrin (PE), CD14-PE, CD34-PE-Cy7 and CD206-allophycocyanin (APC) (BD Biosciences, Franklin Lakes, NJ). Cells were incubated with each antibody for $30 \mathrm{~min}$ (dilution, 1:10) and analyzed using a multicolor flow cytometer (MACS-Quant, Miltenyi Biotec) ( $n=6$ per group). Control gates were set based on staining with a negative isotype control; no more than $0.1 \%$ of cells stained positive using the isotype controls.

\section{Immunohistochemistry}

The excised subcutaneous inguinal fat was fixed with Zinc Fixative (BD Biosciences), paraffin-embedded, sectioned at $5 \mu \mathrm{m}$ and immunostained with the following primary antibodies: guinea pig anti-perilipin (1:200; Progen, Heidelberg, Germany) to stain the cytoplasm of adipocytes, rat anti-MAC2 (1:200; Cedarlane Corp., Burlington, Ontario, Canada) to stain monocytes/macrophages, rabbit anti-CD206 (1:100; Santa Cruz Biotechnology, Dallas, TX) to stain M2 macrophages, goat anti-CD34 (1:100; Santa Cruz Biotechnology) to stain adipose-derived stem cells 
(ASCs), and rabbit anti-von Willebrand factor (vWF; Dako, Santa Clara, CA) to stain vascular endothelial cells (VECs). For double fluorescence staining, appropriate secondary antibodies were used at a dilution of 1:200. An isotype IgG was used as a negative control for each staining step. Nuclei were stained with Hoechst 33342 (1:200; Dojindo, Kumamoto, Japan). Stained slides were examined under a fluorescence microscope (Keyence, Tokyo, Japan). The numbers of M1 and M2 macrophages, ASCs and VECs were counted in at least four field images for each sample ( $\mathrm{n}=6$ per group).

\section{Comparative microarray analysis}

Microarray was performed to analyze relative gene expression in the inguinal fat of HIV-infected and healthy control patients ( $\mathrm{n}=2$ per group). Immediately after harvest, inguinal fat was mechanically homogenized and dissolved with ISOGEN, an RNA extraction reagent (Nippon Gene, Tokyo, Japan). Total RNA was purified using the RNeasy Mini kit (Qiagen, Hilden, Germany) according to the manufacturer's directions. Synthesis of cDNA was performed using the StepOnePlus real-time PCR system (Thermo Fisher Scientific, Waltham, MA) and SuperScript reverse transcriptase (Invitrogen, Waltham, MA). Then, cDNA probes were labeled with Cy3 using a SureTag DNA Labeling kit (Agilent Technologies, Santa Clara, CA) and hybridized with the SurePrint G3 Human GE $8 \times 60$ k Microarray Ver3.0 (G4858A, Agilent Technologies). Microarrays were scanned using a G2505C microarray scanner and read using Feature Extraction Software (Agilent Technologies). Finally, gene expression was analyzed using GeneSpring GX Software, Version 14.9 (Agilent Technologies).

\section{Selected gene expression analysis}

Total RNA was isolated from the inguinal fat of HIVinfected and normal patients using an RNeasy Mini kit, followed by reverse transcription ( $n=6$ per group). Quantitative real-time polymerase chain reaction (PCR) was performed using the StepOnePlus real-time PCR system with fast SYBR Green PCR master mix (Thermo Fisher Scientific); the primer sequences were mainly derived from our previous publication [15], as listed in Tables 1, 2. Expression levels were calculated by the comparative $\mathrm{CT}$ method relative to the mean of two common endogenous reference genes, ACTB and GAPDH [16, 17].

\section{Statistics}

Data were analyzed using SPSS package 23.0 (SPSS, Inc., Chicago, IL) and Kyplot 2.0 (Freeware). Based on the
Table 1 Primer sequences used for real-time PCR

\begin{tabular}{|c|c|c|}
\hline \multirow{2}{*}{$\frac{\text { Gene }}{\mathrm{ACTB}}$} & \multicolumn{2}{|c|}{ Primer sequence $\left(5^{\prime}-3\right)$} \\
\hline & Forward: & ATTGGCAATGAGCGGTTC \\
\hline & Reverse: & GGATGCCACAGGACTCCAT \\
\hline \multirow[t]{2}{*}{ GAPDH } & Forward: & CATGTTCGTCATGGGTGTGAACCA \\
\hline & Reverse: & AGTGATGGCATGGACTGTGGTCAT \\
\hline \multirow[t]{2}{*}{ Leptin } & Forward: & TGCCTTCCAGAAACGTGATCC \\
\hline & Reverse: & CTCTGTGGAGTAGCCTGAAGC \\
\hline \multirow[t]{2}{*}{ PPARY } & Forward: & CTGTTTGCCAAGCTGCTCCAGAAA \\
\hline & Reverse: & AAGAAGGGAAATGTTGGCAGTGGC \\
\hline \multirow[t]{2}{*}{ Adiponectin } & Forward: & TGCTGGGAGCTGTTCTACTG \\
\hline & Reverse: & TACTCCGGTTTCACCGATGTC \\
\hline \multirow[t]{2}{*}{ HIF1a } & Forward: & TTGGCAGCAACGACACAGAAACTG \\
\hline & Reverse: & TTGAGTGCAGGGTCAGCACTACTT \\
\hline \multirow[t]{2}{*}{ TNF-a } & Forward: & AGGACGAACATCCAACCTTCCCAA \\
\hline & Reverse: & TTTGAGCCAGAAGAGGTTGAGGGT \\
\hline \multirow[t]{2}{*}{ PAl-1 } & Forward: & TCTGCCCTCACCAACATTCTGAGT \\
\hline & Reverse: & ACATGTCGGTCATTCCCAGGTTCT \\
\hline \multirow[t]{2}{*}{ GLUT1 } & Forward: & ATCGTGGCCATCTTTGGCTTTGTG \\
\hline & Reverse: & CTGGAAGCACATGCCCACAATGAA \\
\hline
\end{tabular}

ACTB, $\beta$-actin; GAPDH, glyceraldehyde-3-phosphate dehydrogenase; PPAR- $\gamma$, peroxisome proliferator-activated receptor- $;$; HIF-1 $a$, hypoxia-inducible factor-1 $a$; TNF-a, tumor necrosis factor- $a$; PAl-1, plasminogen activator inhibitor-1; GLUT1, glucose transporter 1

The primers sequences were derived from previous publications $[15,16]$

Table 2 Cytometric analyses of stromal vascular fraction extracted from subcutaneous abdominal fat in patients with and without HIV

\begin{tabular}{|c|c|c|c|}
\hline & HIV + & HIV- & $p$-value \\
\hline $\begin{array}{l}\text { Adipose-derived stem cells }\left(\times 10^{5} /\right. \\
\mathrm{ml})\end{array}$ & $0.96 \pm 0.20$ & $1.39 \pm 0.22$ & $0.043^{*}$ \\
\hline $\begin{array}{l}\text { Vascular endothelial cells }\left(\times 10^{4} /\right. \\
\mathrm{ml})\end{array}$ & $9.31 \pm 1.99$ & $6.69 \pm 1.53$ & 0.113 \\
\hline Hematopoietic cells (× 105/ml) & $1.24 \pm 0.28$ & $1.11 \pm 0.17$ & 0.712 \\
\hline Other cells ${ }^{a}\left(\times 10^{4} / \mathrm{ml}\right)$ & $6.67 \pm 1.79$ & $5.05 \pm 1.06$ & 0.103 \\
\hline M1 macrophages $(\%)^{b}$ & $16.1 \pm 4.24$ & $7.08 \pm 1.81$ & $0.014^{*}$ \\
\hline M2 macrophages $(\%)^{b}$ & $42.3 \pm 8.53$ & $53.5 \pm 5.19$ & 0.088 \\
\hline Total macrophages $\left(\times 10^{4} / \mathrm{ml}\right)$ & $4.20 \pm 1.09$ & $3.06 \pm 0.98$ & 0.164 \\
\hline 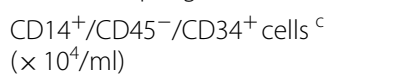 & $6.74 \pm 0.88$ & 0 & $0^{*}$ \\
\hline
\end{tabular}

* Statistically significant

${ }^{a}$ Mural cells, fibroblasts, smooth muscle cells and others

${ }^{b}$ Relative composition of macrophage phenotypes to CD45 + cells

c Possibly derived from bone marrow-derived stem cells

Kolmogorov/Smirnov test, our data were normally distributed within the donor population. Therefore, Welch's $\mathrm{t}$-test was used to assess differences between the two groups. A threshold of $p<0.05$ was considered statistically significant, unless otherwise stated. 


\section{Results}

\section{Cellular analysis}

All study participants were Japanese males with an average age of $42.7 \pm 6.0$ (mean \pm SD) in the HIV+ group and $44.1 \pm 8.3$ in the control group. The history of old NRTIs history of the patients are delineated in Additional file 1 Table S1. The time which has elapsed since the patients received NRTI associated with lipodystrophy were 21.7 years in average (ranged from 19.4 to 26.5 years). None of the patients have currently been administrated neither stavudine, didanosine nor zidovudine. The SVF cells isolated from the abdominal fat of HIV patients and healthy controls were analyzed by flow cytometry. The total cell count and viability of the SVF were $4.2 \pm 0.9 \times 10^{5} / \mathrm{ml}$ and $89.8 \pm 4.3 \%$ in the HIV+ group and $3.9 \pm 0.5 \times 10^{5} / \mathrm{ml}$ and $93.8 \pm 3.1 \%$ in the healthy control group, respectively. There was no significant difference in cell number, viability and viable cell number between the two groups.

Cells from the SVF were characterized on the basis of multiple cell surface antigens. First, a significantly lower number $(p=0.043)$ and relative proportion $(p=0.020)$ of $\mathrm{CD} 45^{-} / \mathrm{CD} 31^{-} / \mathrm{CD} 34^{+}$ASCs was found in the HIV+ group $\left(1.0 \times 10^{5} ; 23.8 \%\right)$ compared with the control group $\left(1.4 \times 10^{5} ; 36.3 \%\right)$ (Fig. $\left.1 \mathrm{~A}\right)$. No significant difference was detected in the number of $\mathrm{CD} 45^{-} / \mathrm{CD} 31^{+} /$ CD34- VECs, hematopoietic cells or other cells between the two groups, although the HIV+ group had a slightly higher number of VECs $\left(0.9 \times 10^{5}\right)$ than the control group $\left(0.7 \times 10^{5}\right)(p=0.113)$. Second, we evaluated the relative frequency of two types of macrophages: $\mathrm{CD}_{4} 5^{+}$/ CD14 ${ }^{+} / \mathrm{CD}_{206}{ }^{-}$inflammatory macrophages (M1) and $\mathrm{CD} 45^{+} / \mathrm{CD} 14^{+} / \mathrm{CD} 206^{+}$anti-inflammatory macrophages (M2). A comparison of the relative frequency of M1 and M2 cells among the CD45 ${ }^{+}$cell subset revealed that fat from HIV-infected patients had significantly more M1 cells compared with healthy samples $(16.1 \%$ vs. $7.1 \%$, $p=0.014)$; however, there was no significant difference in the frequency of M2 cells (42.3\% vs. $53.5 \%, p=0.088)$ or in the total number of macrophages between the two groups $\left(7.3 \times 10^{4}\right.$ vs. $\left.6.8 \times 10^{4}\right)$ (Fig. 1B). Moreover, $\mathrm{CD}_{14}{ }^{+}$cells were analyzed based on patterns of CD 45 and CD34 expression. Whereas healthy control subjects contained only $\mathrm{CD} 45^{+} / \mathrm{CD} 14^{+} / \mathrm{CD} 34^{-}$macrophages, HIV patients showed CD $45^{-} / \mathrm{CD} 14^{+} / \mathrm{CD} 34^{+}$cells, which made up $42.1 \%$ of the $\mathrm{CD} 14^{+}$cell population (Fig. 1C). Representative flow cytometry plots are shown in Fig. 1D.

\section{Immunohistochemistry}

Microsections of inguinal adipose tissues were immunostained to show the cytoplasm of adipocytes (perilipin), macrophages (MAC2), M2 macrophages (CD206), ASCs (CD34), VECs (vWF), and nuclei (Hoechst). The size and shape of adipocytes were similar between the

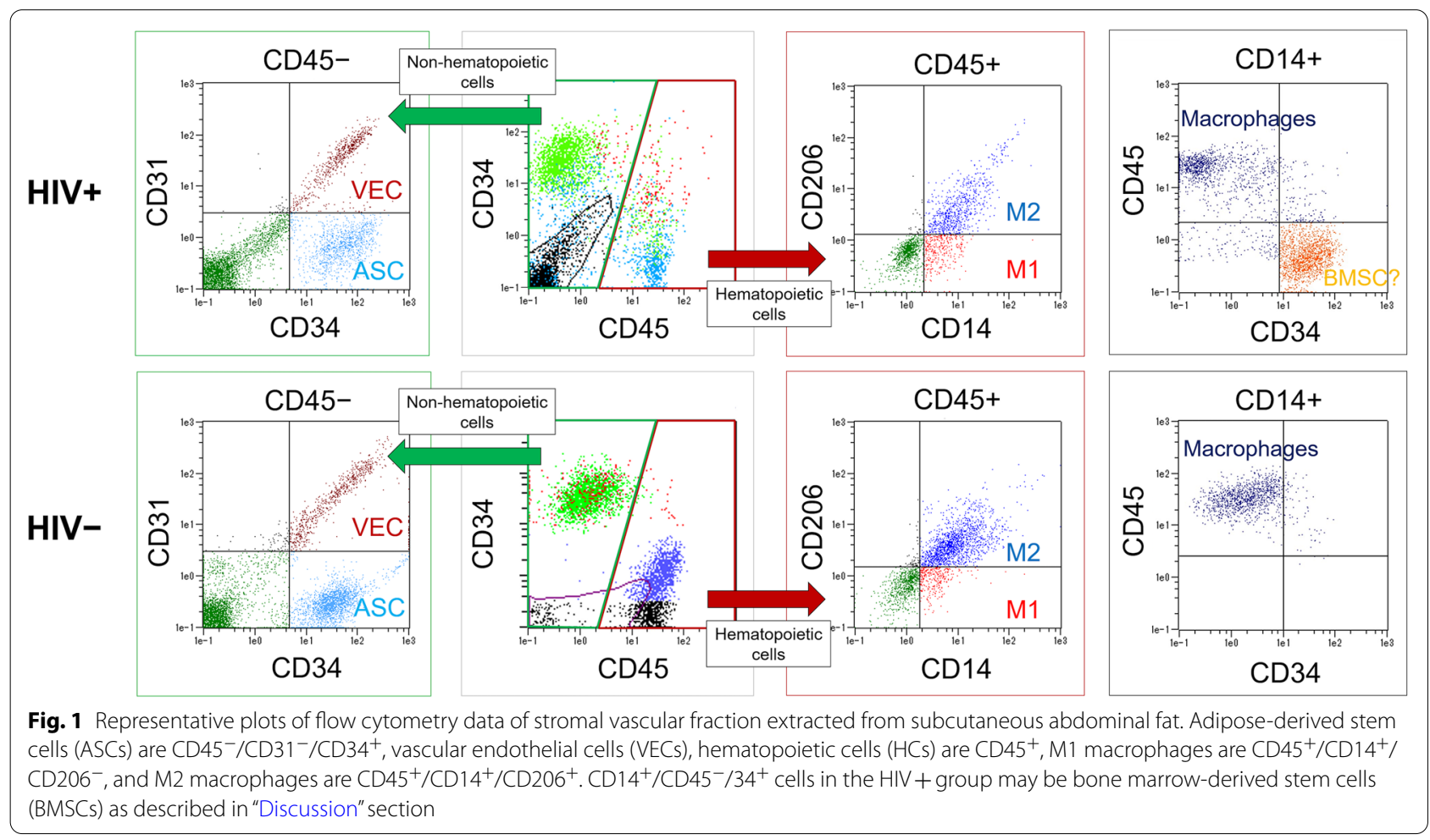


two groups. Whereas most macrophages in the fat from healthy controls were M2 cells, fat from patients with HIV had a significantly larger number of M1 cells $(p=0.030)$, suggesting chronic inflammation (Fig. 2A, B). Although ASCs were observed in samples from both groups, fat samples from patients with HIV contain significantly fewer ASCs $(p=0.002)$, suggesting its impaired adipogenic potential (Fig. 2C, D). With regard to vessel density, although VECs were more abundant in some samples from patients with HIV, the difference was not statistically significant $(p=0.120)$ (Fig. 2E, F).

\section{Comparative gene expression analysis}

Microarray was performed to identify differences in the gene expression profiles of adipose tissue from patients with HIV and healthy controls. Individual analyses were performed on the 9,604 genes that were either 1.5-fold upregulated or downregulated (t test $p<0.05$; 802 entities). Gene ontology analyses of the two populations indicated distinct characteristic ontologies that are summarized in Additional file 2: Fig. S1 and visualized by heat mapping in Fig. 3 and Additional file 3: Fig. S2. Patients with HIV had significant upregulation of genes related to immune activation, insulin resistance and fibrosis, and significant downregulation of genes involved in mitochondrial organization, acyl-CoA synthetase and regulation of apoptosis. Expression of several genes related to mitochondrial function, lipid metabolism and adipogenesis, represented by the corrected intensities of duplicate spots, were shown in Table 3.

Analysis using the Kyoto Encyclopedia of Genes and Genomes (KEGG) database revealed that fat from patients with HIV had gene expression patterns consistent with inhibited insulin signaling and decreased synthesis of triglycerides (Additional file 4: Fig. S3). Additionally, genes encoding elements downstream of peroxisome proliferator-activated receptor- $\gamma(P P A R-\gamma)$ such as $F A B P 4$, perilipin and $A Q P 7$ were downregulated, suggesting inhibited differentiation, maturation and survival of adipocytes as well as reduced fatty acid uptake. Finally, despite having enhanced cAMP signaling, patients with HIV had reduced expression of genes related to lipolysis. All microarray data obtained from our study were deposited with the National Center for Biotechnology Information Gene Expression Omnibus Database (accession no. GSE147162).

\section{Selected gene expression analysis}

The relative expression of several genes in the inguinal fat was confirmed via real-time PCR (Fig. 4). Patients with HIV had significantly decreased expression of key regulatory proteins in adipocytes, PPAR- $\gamma$, adiponectin and leptin, relative to the healthy controls $(p<0.05$ in all). An analysis of obesity-related genes revealed that

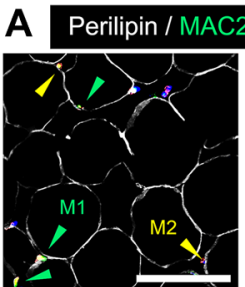

$\mathrm{HIV+}$

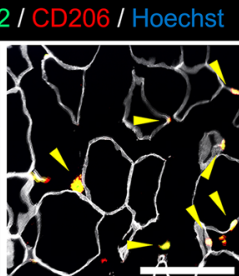

HIV-

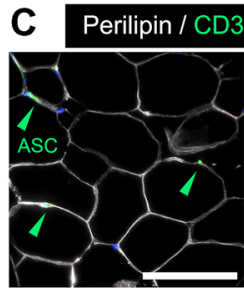

HIV+

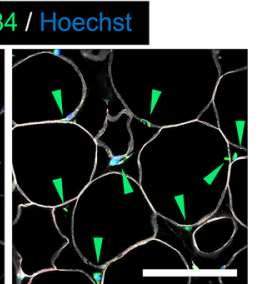

HIV-

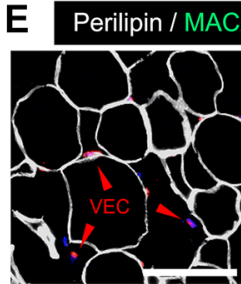

$\mathrm{HIV+}$

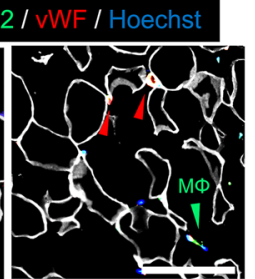

HIV-
B

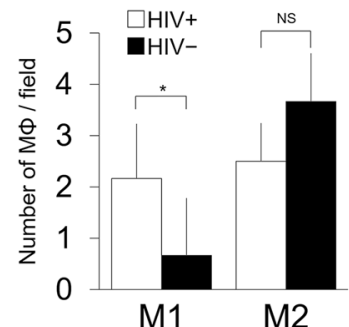

D

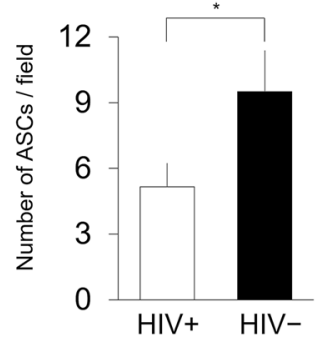

$\mathbf{F}$

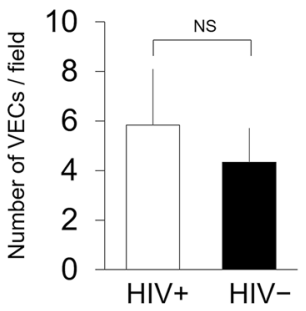

Fig. 2 A Immunohistology for adipocytes (perilipin) and macrophages (MAC2 and CD206) of subcutaneous inguinal adipose tissue. MAC2 ${ }^{+} /$ CD206 ${ }^{-}$macrophages (M1) were observed in fat from HIV patients (green arrows), while the greater part of macrophages were $\mathrm{MAC2}^{+} / \mathrm{CD}^{206^{+}}$(M2) in normal fat (yellow arrows). Scale bars $=100 \mu \mathrm{m}$. B Number of M1 and M2 per field. ${ }^{*} p=0.030$. C Immunohistology for adipose stem cells (ASCs) of subcutaneous inguinal adipose tissue. Fat from patients with HIV had fewer ASCs compared to healthy controls (green arrows). Scale bars $=100 \mu \mathrm{m}$. D Number of ASCs per field. ${ }^{*} p=0.002$. E Immunohistology for vascular endothelial cells (VECs) of subcutaneous inguinal adipose tissue. VECs were more abundant in fat from patients with HIV. vWF; von Willebrand factor. MФ; macrophage. Scale bars $=100 \mu \mathrm{m}$. F Number of VECs per field. The number of VECs did not differ significantly 


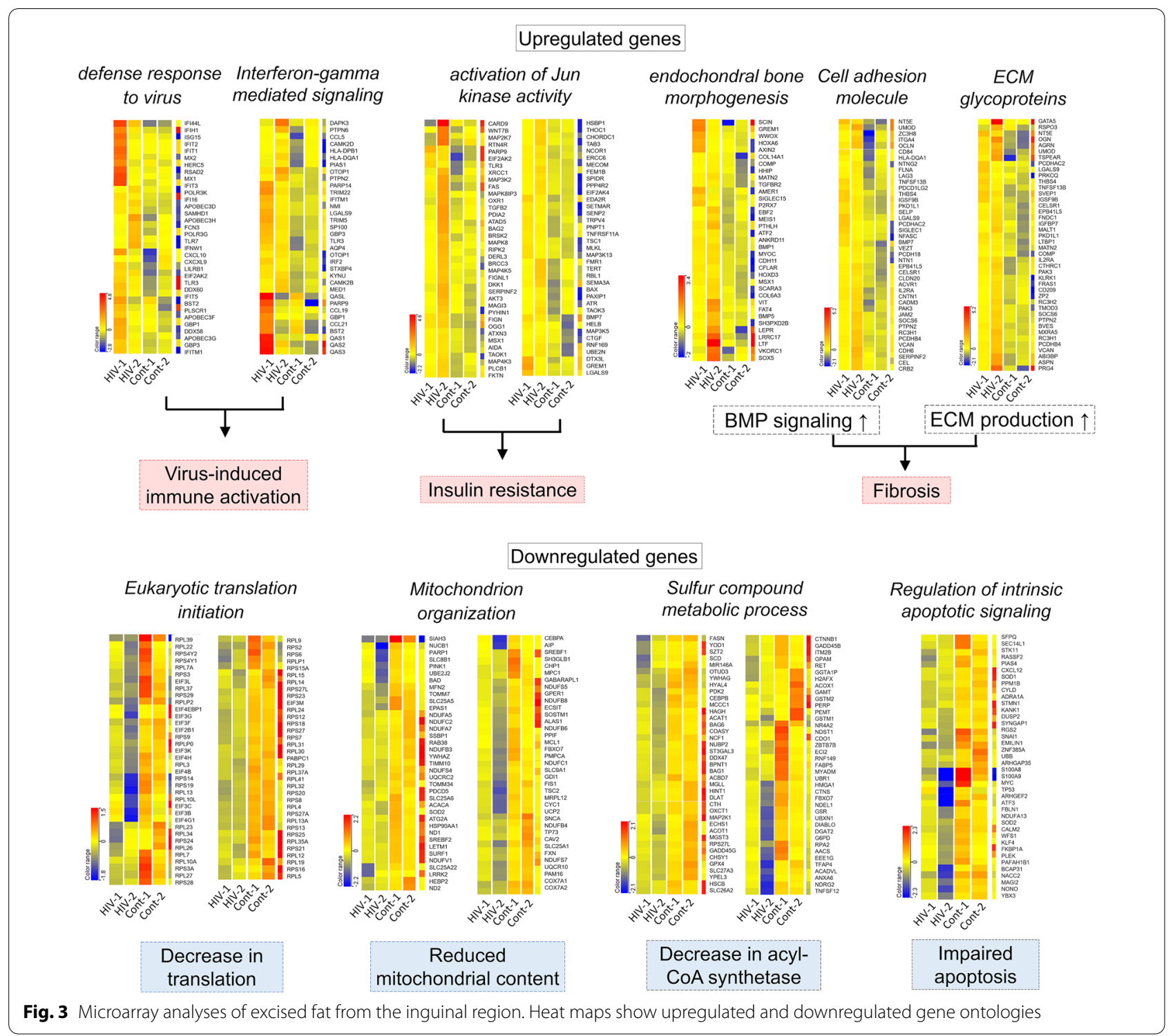

patients with HIV had significantly higher expression of PAI- 1 and HIF- $1 \alpha(p<0.05$ in both) and not significantly different expression of GLUT1. Expression of TNF- $\alpha$, an inflammatory cytokine, was greatly upregulated in patients with HIV $(p=0.009)$.

\section{Discussion}

Although older NRTIs which mostly induce lipodystrophy are rarely used in the current clinical practice, the patients who had been treated with such NRTIs continue to live with lipodystrophy. Therefore, there is still a need for elucidation of the pathologic mechanism of HIV-lipodystrophy, to actualize better treatment of those patients. Moreover, as many investigators have previously reported, HIV-associated lipodystrophy is the result of a complex interplay between the HIV-1 virus, toxic side effects of antiretroviral drugs and host characteristics [18]. Subtle changes in fat quantity and metabolism were observed in patients with HIV prior to the use of antiretroviral drugs [19], in patients with other infections (e.g., tuberculosis) [20] and in patients with non-infectious proinflammatory conditions (e.g., malignancy-induced cachexia) [21]. Thus, considering the pathogenesis of HIV-associated lipodystrophy from the perspective of an immune-metabolic imbalance seems to be useful for further understanding of various diseases presenting lipodystrophic condition. 
Table 3 Comparison of gene expression data extracted by microarray

\begin{tabular}{llll}
\hline Gene & HIV + & HIV- & HIV+/HIV- \\
\hline $\begin{array}{l}\text { Mitochondrial energy } \\
\text { metabolism }\end{array}$ & & & \\
COX3 & 0.77 & 1.33 & 0.58 \\
$\begin{array}{l}\text { Mitochondrial biogenesis } \\
\text { POLG1 }\end{array}$ & 0.81 & 1.00 & 0.81 \\
Lipid metabolism & & & \\
FASN & 0.57 & 1.39 & 0.41 \\
Adipogenesis & & & \\
CEBPB & 0.69 & 1.34 & 0.51 \\
SREBF1 & 0.88 & 1.41 & 0.63 \\
PPARG & 0.84 & 1.12 & 0.75 \\
LMNA & 0.76 & 1.18 & 0.64 \\
KLF15 & 0.52 & 1.25 & 0.42 \\
Apoptosis & & & \\
FAS & 1.87 & 0.73 & 2.56 \\
TNFAIP3 & 1.29 & 0.96 & 1.35 \\
SOD1 & 1.29 & 1.00 & 1.29 \\
\hline
\end{tabular}

The values shown are the average of individual intensities of duplicate spots COX3, cytochrome coxidase subunit III; POLG1, polymerase $\gamma$ (catalytic subunit); FASN, fatty acid synthase; CEBPB, CCAAT/enhancer binding protein $\beta ;$ SREBF1, sterol regulatory element-binding transcription factor 1 ; PPARG, peroxisome proliferator-activated receptor gamma; $L M N A$, Lamin $\mathrm{A} ; K L F 15$, kruppel-like transcription factor $15 ; F A S$, factor of apoptotic stimulus; TNFA, tumor necrosis factor alfa; SOD1, increase of superoxide dismutase 1

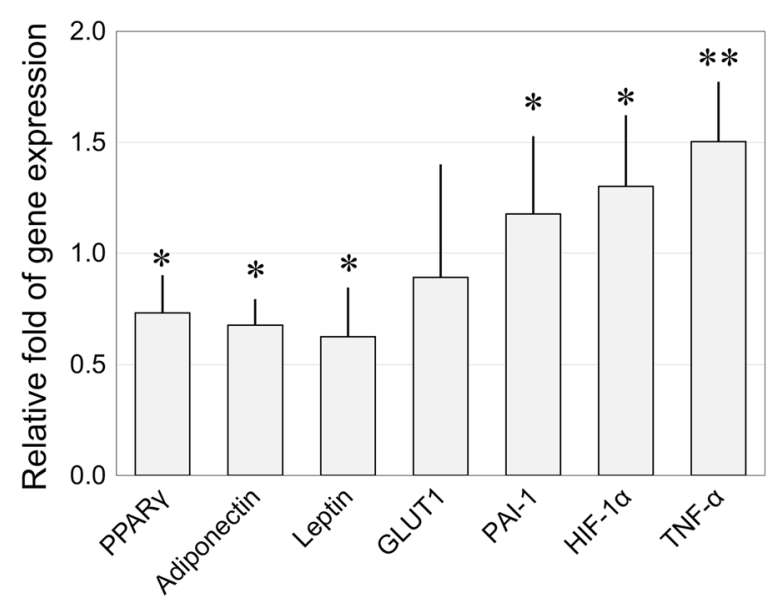

Fig. 4 Transcriptional profiles of inguinal adipose tissues of patients with HIV-1 compared to healthy controls, quantified by real-time $P C R$. There was a decrease in key regulatory proteins of adipocytes including PPAR- $\gamma$ (peroxisome proliferator-activated receptor), adiponectin and leptin and an increase in inflammation-associated genes including PAI (plasminogen activator inhibitor)-1, HIF (hypoxia-inducible factor)- $1 a$ and TNF-a (tumor necrosis factor). GLUT1; glucose transporter 1. ${ }^{*} p<0.05,{ }^{* *} p<0.01$

\section{Adipose-derived stem cells in HIV-associated} lipodystrophy

We compared the cellular composition of SVF isolated from the abdominal fat of lipodystrophic patients with HIV and healthy controls using flow cytometry. First, we focused on ASCs which play a central role in the regeneration of adipose tissue, by differentiation into adipocytes and release of angiogenic factors [22]. There were fewer ASCs in fat from patients with HIV compared to healthy patients. This decrease in ASC quantity was also confirmed by immunohistochemistry. We believe this is due to the exhaustion of ASCs in the process of sustained and progressive lipoatrophy. On the other hand, there was no significant difference in the number of VECs, hematopoietic cells, or total SVF cells in patients with HIV. Though not a statistically significant difference, patients with HIV had a higher average number of VECs $(p=0.113)$, in good agreement with several previous reports [23].

\section{Macrophages in HIV-associated lipodystrophy}

Macrophages are a key modulator of the immune response to pathogens. In this work, we measured inflammatory macrophages (M1) and anti-inflammatory macrophages (M2), which are typically regarded as the two extremes in a continuum of functional macrophage phenotypes [24]. We found that fat from lipodystrophic patients with HIV contained a significantly greater number of $\mathrm{M} 1$ relative to healthy controls, whereas there was no significant difference in M2 or in total number of macrophages between the two groups. Because monocytes and macrophages expressing CD14 are more susceptible to HIV infection, the host immune response to viral infection rather than the drug toxicity is of particular importance in this shift of macrophages toward M1 phenotype [25]. Increased infiltration of M1 macrophages leads to the production of proinflammatory cytokines that result in inflammation and functional impairment of adipocytes [26].

Another interesting finding in this study was the presence of $\mathrm{CD} 45^{-} / \mathrm{CD} 14^{+} / \mathrm{CD} 34^{+}$cells in fat from patients with HIV (comprising $42.1 \%$ of all CD14 ${ }^{+}$cells), which were not observed in healthy controls. Usually, CD $45^{+}$ hematopoietic stem cells differentiate into $\mathrm{CD} 14^{+}$monocytes in the bone marrow. However, previous studies have reported the isolation of $\mathrm{CD} 45^{-} / \mathrm{CD} 14^{+} / \mathrm{CD} 34^{+}$ low-adherent multipotent mesenchymal cells from the bone marrow [27]. In addition, after HIV-infected monocytes/macrophages extravasate from the bloodstream to tissues, they reside for a longer period of time than noninfected cells [28], and long-term residence in adipose tissue decreases CD45 expression of the cells [14, 27]. Actually, we reported a subpopulation of CD $45^{+} / \mathrm{CD} 14^{+} /$ 
$\mathrm{CD} 4^{+}$macrophages localized in the perivascular region of adipose tissue in healthy patients, which were capable of differentiating into multiple mesenchymal lineages and lost expression of CD45 by passage 3 resulting in an expression profile similar to ASCs [29]. Thus, we hypothesize that the $\mathrm{CD} 45^{-} / \mathrm{CD} 14^{+} / \mathrm{CD} 34^{+}$cells found in this study are bone marrow-derived stem cells that migrated to HIV-infected fat in compensatory response to ASC deficiency and lipoatrophy, however, additional work is required to address the specific origin of this cell population.

Inflammation and fibrosis in HIV-associated lipodystrophy We previously found that more than $90 \%$ of macrophages that reside in normal adipose tissue are M2 phenotype [29]. While adipose tissue-resident M2 cells are involved in tissue remodeling and anti-inflammatory reactions [30], M1 cells cause inflammation and impair adipocyte function leading to insulin resistance and dyslipidemia, which was also confirmed in HIV-infected lipoatrophic patients in previous reports $[26,31]$. The qualitative change in macrophage phenotype from M2 into M1 is typically observed in obesity, where adipocyte hypertrophy is accompanied by higher numbers of macrophages and a greater polarization toward proinflammatory M1 cytokine phenotypes [32]. Prior evidence of macrophage activation and inflammation in the subcutaneous fat of individuals with insulin resistance implies the mechanistic similarity between HIV-associated lipodystrophy and metabolic disorders [33].

Comparative gene analyses of fat samples from patients with and without HIV produced data that mirrored our flow cytometric findings. Genes related to host immune responses and inflammation were upregulated in the HIV+group, suggesting that activated M1 [26] and $\mathrm{CD} 4^{+} \mathrm{T}$ cells [34] were potential sources of proinflammatory cytokine production. Besides, expression of genes responsible for extracellular matrix production was upregulated in the HIV+ group, suggesting progressive fibrosis. Fibrosis, which was also described in the context of other organs such as the liver and myocardium in HIV patients, indicates a proinflammatory and profibrotic state of adipose tissue [35].

\section{Adipocyte dysfunction by mitochondrial toxicity}

Since the introduction of NRTIs in the mid-1990s, mitochondrial toxicity has been documented as the most severe form of ART-induced adipocyte toxicity. Adipocyte mitochondria plays a central role in metabolism, energy expenditure and clearance of reactive oxygen species. During adipocyte differentiation, mitochondrial activity dramatically increases to promote adipogenesis and maturation into adipocytes [36]. Thus, mitochondrial dysfunction in adipocytes is often accompanied by impaired fatty acid metabolism, disturbed oxidative phosphorylation, altered adipokine secretion and reduced glucose uptake [37], resulting in inhibited adipogenesis and activated apoptosis.

Our study revealed decreased expression of several genes involved in mitochondrial function in fat from HIV patients, including inhibited expression of POLG1 which was suggested as one of key factors in NRTI-induced lipoatrophy [8]. Relatedly, we found that transcription factors important to adipogenesis such as SREBF1 [38], $C E B P B$ [39], and PPARG [40, 41] were downregulated in patients with HIV in accordance with previous studies $[17,26,41]$. Oxidative stress due to mitochondrial toxicity, indicated by an upregulation of $S O D 1$, also causes inflammation and accelerates apoptosis [42]. In particular, our finding of remarkably increased TNF- $\alpha$ (which is associated with inflammation and apoptosis) in HIV patients is in good agreement with prior studies [42]. Key regulatory genes of apoptosis such as Fas were also upregulated in patients with HIV in this study. All these findings reflect impairment of adipocyte differentiation and function, due to mitochondrial toxicity.

\section{Changes in lipid metabolism and fat distribution}

Fat redistribution in HIV-infected patients are considered consequence of metabolic complications including toxicity of old NRTIs. According to previous reports, HIV patients with lipodystrophy present with a higher index of total lipolysis [43] and increased circulating free fatty acids [17, 43, 44] compared to HIV-negative controls. In our study, however, KEGG pathway analysis revealed a lower index of lipolysis in HIV patients. Nevertheless, inhibited synthesis of triglycerides and reduced intake of free fatty acid causes elevated free fatty acids [45], which induces inflammatory M1 migration, decreases adiponectin production and leads to insulin resistance in adipocytes [43].

Our results may help elucidate the etiology of fat redistribution in patients with HIV. The accumulation of visceral fat after HIV infection is often accompanied by systemic inflammation, insulin resistance, dyslipidemia and an increased risk of cardiovascular diseases [46, 47]; very similar to the profile of patients with metabolic syndrome. Although the acute phase of inflammation accelerates lipolysis, chronic inflammation causes insulin resistance which is strongly associated with dysregulated lipolysis and dyslipidemia (increased triglycerides). Of interest, previous reports have suggested that visceral adipocytes are less susceptible to the toxicity of older NRTIs relative to subcutaneous adipocytes, as measured by decreases in gene expression of PPAR- $\gamma$ [48-50] and so on, potentially due to their higher mitochondrial 
content. Thus, visceral fat, which retains most of its mitochondrial function despite NRTI treatment, may expand in the presence of an inflammatory environment and impaired insulin-stimulated glucose uptake resulting in central obesity. On the contrary, subcutaneous fat, which is sensitive to NRTI toxicity, is more severely damaged resulting in peripheral lipoatrophy. Therefore, we hypothesize that identical inflammatory conditions cause opposite effects for different types of fat, depending on their sensitivity to mitochondrial toxicity of NRTIs. Previous studies showed that stopping or replacing older NRTI medications often leads to improvements in limb fat atrophy but not in visceral fat accumulation [51, 52], which may support our hypothesis because metabolic changes are hard to restore compared to direct adverse drug reactions.

This study has several limitations. This is a very small case series. We carefully analyzed abdominal and inguinal subcutaneous adipose tissues, however, collecting samples from the same location would be more desirable approach. Also, these sites were the areas usually affected by lipohypertrophy [53], and additional analyses of the areas severely affected by lipoatrophy (such as face and limbs) might be helpful for further understanding of pathology of HIV-associated lipodystrophy. Finally, The pathogenesis of lipodystrophy we provided is inferential, and additional researches are required to validate its reliability.

\section{Supplementary Information}

The online version contains supplementary material available at https://doi. org/10.1186/s12981-022-00432-9.

Additional file 1: Table S1. The history of antiretroviral therapy of the patients with HIV-associated lipodystrophy.

Additional file 2: Figure S1. Summary of the functional categories of genes differentially expressed in adipose tissue from lipodystrophic patients with HIV.

Additional file 3: Figure S2. Heat maps of upregulated and downregulated gene ontologies.

Additional file 4: Figure S4. KEGG pathway analysis suggested inhibited insulin signaling, reduced adipocyte differentiation and function, and decreased synthesis of triglycerides and lipolysis in the subcutaneous far from HIV+ group.

\section{Acknowledgements}

We greatly appreciate Mrs. Takako Shirado's substantial help with data collection and analysis in support of this work.

\section{Authors' contributions}

TM performed the conception and design; collection, and/or assembly of data; data analysis and interpretation; figures; and manuscript writing. KT, S-HW, KK, RA and MM performed the collection and/or assembly of data. HT and AK performed the collection and/or assembly of data, data analysis, and interpretation. SO performed the data analysis and interpretation, administrative support. KY performed the conception and design; data analysis and interpretation; financial support; administrative support; final approval of manuscript; and manuscript writing. All authors read and approved the final manuscript.

\section{Funding}

This study was supported in part by Science Research Grants on HIV/AIDS (H25-AIDS-G-001 and H28-AIDS-G-002) from the Ministry of Health, Labour and Welfare of Japan. The funding source had no involvement in the study.

\section{Availability of data and materials}

The datasets generated and/or analyzed during the current study are not publicly available due to ethical and legal reasons, but are available from the corresponding author on reasonable request.

\section{Declarations}

\section{Ethics approval and consent to participate}

This study was approved by the ethics committee from the institutional review board of National Center for Global Health and Medicine (NCGM; Tokyo, Japan) (NCGM-G-001598-00).

\section{Consent for publication}

Not applicable.

\section{Competing interests}

The authors declare that they have no competing interests.

\section{Author details}

${ }^{1}$ Department of Plastic Surgery, Jichi Medical University, 3311-1, Yakushiji, Shimotsuke-Shi, Tochigi 329-0498, Japan. ${ }^{2}$ Department of Plastic Surgery, University of Tokyo, 7-3-1, Hongo, Bunkyo-Ku, Tokyo 113-8655, Japan. ${ }^{3}$ AIDS Clinical Center, National Center for Global Health and Medicine, 1-21-1, Toyama, Shinjuku-ku, Tokyo 162-8655, Japan. ${ }^{4}$ Stem Cell Technologies Laboratory, Graduate School of Biological Sciences, Nara Institute of Science and Technology, 8916-5, Takayama, Ikoma, Nara 630-0192, Japan.

Received: 21 August 2021 Accepted: 31 January 2022

Published online: 04 March 2022

\section{References}

1. Miuma S, Hidaka M, Takatsuki M, Natsuda K, Soyama A, Miyaaki H, et al. Current characteristics of hemophilia patients co-injected with HIV/HCV in Japan. Exp Ther Med. 2018;15:2148-55.

2. Nakagawa F, Lodwick RK, Smith CJ, Smith R, Cambiano V, Lundgren JD, et al. Projected life expectancy of people with HIV according to timing of diagnosis. AIDS. 2012;26:335-43.

3. Bacchetti P, Gripshover B, Grunfeld C, Heymsfield SB. Fat distribution in men with HIV infection. J Acquir Immune Defic Syndr. 2005:40:121-31.

4. Mallon PW, Miller J, Cooper DA, Carr A. Prospective evaluation of the effects of antiretroviral therapy on body composition in HIV-1-infected men starting therapy. AIDS. 2003;17:971-9.

5. Jacobson DL, KnoxT, Spiegelman D, Skinner S, Gorbach S, Wanke C. Prevalence of, evolution of, and risk factors for fat atrophy and fat deposition in a cohort of HIV-infected men and women. Clin Infect Dis. 2005;40:1837-45.

6. Friis-Møller N, Weber R, Reiss P, Thiébaut R, Kirk O, Monforte A, et al. Cardiovascular disease risk factors in HIV patients-association with antiretroviral therapy, Results from the DAD study. AIDS. 2003;17:1179-93.

7. Gibellini L, De Biasi S, Nasi M, Carnevale G, Pisciotta A, Bianchini E, et al. Different origin of adipogenic stem cells influences the response to antiretroviral drugs. Exp Cell Res. 2015;337:160-9.

8. Brinkman K, Smeitink JA, Romijin JA, Reiss P. Mitochondrial toxicity induced by nucleoside analogue reverse-transcriptase inhibitors is a key factor in the pathogenesis of antiretroviral-therapy-related lipodystrophy. Lancet. 1999:354:1112-5.

9. Joky V, Flandre P, Meiffredy V, Leturque N, Harel M, Aboulker JP, et al. Increased risk of lipoatrophy under stavudine in HIV-1-infected patients: results of a substudy from a comparative trial. AIDS. 2002;16:2447-54.

10. Ho D, Jagdeo J. Safety and efficacy of a volumizing hyaluronic acid filler for treatment of HIV-associated facial lipoatrophy. JAMA Dermatol. 2017:153:61-5. 
11. Bechara FG, Gambichler T, Brockmeyer NH, Sand M, Altmeyer P, Hoffmann K. Hyaluronic acid new formulation: experience in HIV-associated facial lipoatrophy. Dermatology. 2008;217:244-9.

12. Shuck J, lorio ML, Hung R, Davison SP. Autologous fat grafting and injectable dermal fillers for human immunodeficiency virus-associated facial lipodystrophy: a comparison of safety, efficacy, and long-term treatment outcomes. Plast Reconstr Surg. 2013;131:499-506.

13. Burnouf $M$, Buffet $M$, Schwarzinger $M$, Roman P, Bui P, Prévot $M$, et al. Evaluation of Coleman lipostructure for treatment of facial lipoatrophy in patients with human immunodeficiency virus and parameters associated with the efficiency of this technique. Arch Dermatol. 2005;141:1220-4.

14. Yoshimura K, Shigeura T, Matsumoto D, Sato T, Takaki Y, Aiba-Kojima E, et al. Characterization of freshly isolated and cultured cells derived from the fatty and fluid portions of liposuction aspirates. J Cell Physiol. 2006;208:64-76.

15. Suga H, Eto H, Inoue K, Aoi N, Kato H, Araki J, et al. Cellular and molecular features of lipoma tissue: comparison with normal adipose tissue. $\mathrm{Br} J$ Dermatol. 2009;161:819-25.

16. Silver N, Best S, Jiang J, Thein SL. Selection of housekeeping genes for gene expression studies in human reticulocytes using real-time PCR. BMC Mol Biol. 2006;7:33.

17. Sievers M, Walker UA, Sevastianova K, Setzer B, Wågsäter D, Eriksson P, et al. Gene expression and immunohistochemistry in adipose tissue of HIV type 1-infected patients with nucleoside analogue reverse-transcriptase inhibitor-associated lipoatrophy. J Infect Dis. 2009;200:252-62.

18. Koethe JR. Adipose tissue in HIV infection. Compr Physiol. 2017;7:1339-57.

19. Macallan DC, Noble C, Baldwin C, Jebb SA, Prentice AM, Coward WA, et al. Energy expenditure and wasting in human immunodeficiency virus infection. N Engl J Med. 1995;333:83-8.

20. Juffermans NP, Verbon A, van Deventer SJ, van Deutekom H, Speelman P, van der Poll T. Tumor necrosis factor and interleukin-1 inhibitors as markers of disease activity of tuberculosis. Am J Respir Crit Care Med. 1998;157:1328-31.

21. Batista ML Jr, Peres SB, McDonald ME, Alcantara PS, Olivan M, Otoch JP, et al. Adipose tissue inflammation and cancercachexia: Possible role of nuclear transcription factors. Cytokine. 2012;57:9-16.

22. Mashiko T, Yoshimura K. How does fat survive and remodel after grafting? Clin Plast Surg. 2015;42:181-90

23. Jan V, Cervera P, Maachi M, Baudrimont M, Kim M, Vidal H, et al. Altered fat differentiation and adipocytokine expression are inter-related and linked to morphological changes and insulin resistance in HIV-1-infected lipodystrophic patients. Antivir Ther. 2004;9:555-64.

24. Gordon S. Alternative activation of macrophages. Nat Rev Immunol. 2003;3:23-35.

25. Jaworowski A, Kamwendo DD, Ellery P, Sonza S, Mwapasa V, Tadesse E, et al. CD16+ monocyte subset preferentially harbors HIV-1 and is expanded in pregnant Malawian women with Plasmodium falciparum malaria and HIV-1 infection. J Infect Dis. 2007;196:38-42

26. Shikuma CM, Gangcuangco LM, Killebrew DA, Libutti DE, Chow DC, Nakamoto BK, et al. The role of HIV and monocytes/macrophages in adipose tissue biology. J Acquir Immune Defic Syndr. 2014;65:151-9.

27. Szade K, Zuba-Surma E, Rutkowski AJ, Jozkowicz A, Dulak J. CD45CD14+CD34+ murine bone marrow low-adherent mesenchymal primitive cells preserve multilineage differentiation potential in long-term in vitro culture. Mol Cells. 2011;31:497-507.

28. Westhorpe CL, Zhou J, Webster NL, Kalionis B, Lewin SR, Jaworowski A, et al. Effects of HIV-1 infection in vitro on transendothelial migration by monocytes and monocyte-derived macrophages. J Leukoc Biol. 2009;85:1027-35.

29. Eto H, Ishimine H, Kinoshita K, Watanabe-Susaki K, Kato H, Doi K, et al. Characterization of human adipose tissue-resident hematopoietic cell populations reveals a novel macrophage subpopulation with CD34 expression and mesenchymal multipotency. Stem Cells Dev. 2013;22:985-97.

30. Satoh T, Kidoya H, Naito H, Yamamoto M, Takemura N, Nakagawa K, et al. Critical role of Trib1 in differentiation of tissue-resident M2-like macrophages. Nature. 2013;495:524-8.

31. Lloreta J, Domingo P, Pujol RM, Arroyo JA, Baixeras N, Matias-Guiu X, et al. Ultrastructural features of highly active antiretroviral therapy-associated partial lipodystrophy. Virchows Arch. 2002:441:599-604.

32. Nishimura S, Manabe I, Nagasaki M, Eto K, Yamashita H, Ohsugi M, et al. CD8+ effector $T$ cells contribute to macrophage recruitment and adipose tissue inflammation in obesity. Nat Med. 2009;15:914-20.
33. Lawler HM, Underkofler CM, Kern PA, Erickson C, Bredbeck B, Rasouli N. Adipose tissue hypoxia, inflammation and fibrosis in obese insulin sensitive and obese insulin resistant subjects. J Clin Endocrinol Metab. 2016:101:1422-8.

34. Couturier J, Suliburk JW, Brown JM, Luke DJ, Agarwal N, Yu X, et al. Human adipose tissue as a reservoir for memory CD4+ T cells and HIV. AIDS. 2015;29:667-74

35. Thiara DK, Liu CY, Raman F, Mangat S, Purdy JB, Duarte HA, et al. Abnormal myocardial function is related to myocardial steatosis and diffuse myocardial fibrosis in HIV-infected adults. J Infect Dis. 2015;212:1544-51.

36. Bogacka I, Xie H, Bray GA, Smith SR. Pioglitazone induces mitochondrial biogenesis in human subcutaneous adipose tissue in vivo. Diabetes. 2005:54:1392-9.

37. Newgard CB. Interplay between lipids and branched-chain amino acids in development of insulin resistance. Cell Metab. 2012:15:606-14

38. Walker AK, Jacobs RL, Watts JL, Rottiers V, Jiang K, Finnegan DM, et al. A conserved SREBP-1/phosphatidylcholine feedback circuit regulates lipogenesis in metazoans. Cell. 2011;147:840-52.

39. Yu H, He K, Wang L, Hu J, Gu J, Zhou C, et al. Stk40 represses adipogenesis through translational control of CCAAT/enhancer-binding proteins. J Cell Sci. 2015;128:2881-90.

40. Semple RK, Chatterjee VK, O'Rahilly S. PPAR gamma and human metabolic disease. J Clin Invest. 2006;116:581-9.

41. Bastard JP, Caron M, Vidal H, Jan V, Auclair M, Vigouroux C, et al. Association between altered expression of adipogenic factor SREBP1 in lipoatrophic adipose tissue from HIV-1-infected patients and abnormal adipocyte differentiation and insulin resistance. Lancet. 2002;359:1026-31.

42. McComsey GA, Paulsen DM, Lonergan J, Hessenthaler SM, Hoppel CL, Williams VC, et al. Improvements in lipoatrophy, mitochondrial DNA levels and fat apoptosis after replacing stavudine with abacavir or zidovudine. AIDS. 2005;19:15-23.

43. Gorjao R, Cury-Boaventura MF, de Lima TM, Curi R. Regulation of human lymphocyte proliferation by fatty acids. Cell Biochem Funct. 2007;25:305-15.

44. Hadigan C, Borgonha S, Rabe J, Young V, Grinspoon S. Increased rates of lipolysis among human immunodeficiency virus-infected men receiving highly active antiretroviral therapy. Metabolism. 2002;51:1143-7.

45. Stanley TL, Grinspoon SK. Body composition and metabolic changes in HIVinfected patients. J Infect Dis. 2012;205:S383-390.

46. Howard LC, Liu CY, Purdy JB, Walter P, Bluemke DA, Hadigan C. Lipolytic rate associated with intramyocardial lipid in an HIV cohort without increased lipolysis. J Clin Endocrinol Metab. 2016;101:151-6.

47. Grunfeld C, Rimland D, Gibert CL, Powderly WG, Sidney S, Shlipak MG, et al. Association of upper trunk and visceral adipose tissue volume with insulin resistance in control and HIV-infected subjects in the FRAM study. J Acquir Immune Defic Syndr. 2007:46:283-90.

48. Gallego-Escuredo JM, Villarroya J, Domingo P, Targarona EM, Alegre M, Domingo JC, et al. Differentially altered molecular signature of visceral adipose tissue in HIV-1-associated lipodystrophy. J Acquir Immune Defic Syndr. 2013:64:142-8

49. Leroyer S, Vatier C, Kadiri S, Quette J, Chapron C, Capeau J, et al. Glyceroneogenesis is inhibited through HIV protease inhibitor-induced inflammation in human subcutaneous but not visceral adipose tissue. J Lipid Res. 2011:52:207-20.

50. Walker UA, Lebrecht D, Reichard W, Kirschner J, Bissé E, Iversen L, et al. Zidovudine induces visceral mitochondrial toxicity and intra-abdominal fat gain in a rodent model of lipodystrophy. Antivir Ther. 2014;19:783-92.

51. Moyle GJ, Baldwin C, Langroudi B, Mandalia S, Gazzard BG. A 48-week, randomized, open-label comparison of three abacavir-based substitution approaches in the management of dyslipidemia and peripheral lipoatrophy. J Acquir Immune Defic Syndr. 2003;33:22-8.

52. Barreiro P, Soriano V, Blanco F, Casimiro C, de la Cruz JJ, Gonzalez-Lahoz J. Risks and benefits of replacing protease inhibitors by nevirapine in HIVinfected subjects under long-term successful triple combination therapy. AIDS. 2000;14:807-12.

53. Koethe JR, Lagathu C, Lake JE, Domingo P, Calmy A, Falutz J, et al. HIV and antiretroviral therapy-related fat alterations. Nat Rev Dis Primers. 2020;6:48.

\section{Publisher's Note}

Springer Nature remains neutral with regard to jurisdictional claims in published maps and institutional affiliations. 